\title{
People, technology, and governance for sustainability: the contribution of systems and cyber-systemic thinking
}

\author{
Sergio Barile ${ }^{1} \cdot$ Fabio Orecchini $^{2} \cdot$ Marialuisa Saviano $^{3} \cdot$ Francesca Farioli $^{4}$
}

Published online: 24 August 2018

(C) Springer Japan KK, part of Springer Nature 2018

\section{Introduction}

We live in an ever-increasing unsustainable world in which sustainability shows to be a complex multidimensional and multi-stakeholder problem. The complexity to address is increasingly beyond our traditional response capabilities. Hence the challenge is "how we account for this complexity in the quest for a sustainable world underpinned by inclusion and fairness" (Espejo 2018). What is required is to account for the "individual and cumulative social, environmental and economic implications of decision or process based on an understanding of the systemic nature of the world, the interconnectedness of natural and human systems", and for the "direct and indirect consequences for people and ecosystems based on an understanding of the global nature of the world and how local and regional issues are part of the whole" (Crofton 2000: 400).

People and technology are key resources for addressing the above challenge. Dominant interpretative and

Marialuisa Saviano

msaviano@unisa.it

Sergio Barile

sergio.barile@uniroma1.it

Fabio Orecchini

f.orecchini@unimarconi.it

Francesca Farioli

francesca.farioli@gmail.com

1 Sapienza University of Rome, Rome, Italy

2 Marconi University, Italian Association for Sustainability Science (IASS), Rome, Italy

3 University of Salerno, IASS, Italian Association for Sustainability Science, Via Giovanni Paolo II, Rome 84084, Fisciano (SA), Italy

4 IASS, Italian Association for Sustainability Science, Rome, Italy governance approaches, however, tend to reduce complex problems to the application of techno-centric knowledge and pseudo-solutions focusing on single aspects of the problems instead of trying to capture and read their complexity as a whole. Governance in such complex contexts requires challenging our dominant thinking, practices,institutions and development narratives (Ison 2017, http:// wosc2017rome.asvsa.org/).

Any phenomenon of reality relevant to the goals of sustainability and sustainable development is indeed characterized by highly interconnected dynamics that involve a variety of ecological, social and economic dimensions that cannot be effectively analysed in isolation (Holling 2001).

When dealing with such complex, interrelated, realworld, riddled with uncertainties and contested problems disciplinary knowledge requires being effectively integrated and linked to action (Best and Holmes 2010). Inter- and trans-disciplinary approaches are needed in order a body of knowledge can be co-produced which is capable of overcoming the limits of still fragmented and specialized disciplines and capable to include all perspectives, interests, values of all actors involved or affected (Barile et al. 2018a). Active collaboration with various stakeholders throughout society - transdisciplinarity-must form a critical component of sustainability science" (Yarime et al. 2012: 101).

Since its origins, Sustainability Science has been engaged in such missions, providing a platform for building a corpus of knowledge which can "point the way to a sustainable global society by facing challenges that existing disciplines have not addressed" (https://link.springer. com/journal/11625): although the academic landscape has constantly evolved over the years, shifting from discussions focused on specialized fields to an interdisciplinary debate that pursues a comprehensive understanding of social, economic and ecological systems, there is still much work to do (Komiyama and Takeuchi 2006; Orecchini et al. 2012; Wiek et al. 2012). 
Many scholars highlight these still-unfulfilled needs, as follows:

- "The problems needing to be addressed are complex and interconnected; they cannot be understood through the lens of a single specialization and they cannot be solved when isolated into compartments. Sustainability leaders will need the ability to be flexible and innovative, to think and communicate with others outside narrow disciplines" (Robertson 2014: 309);

- "While furnished with a diverse range of perspectives and approaches, development practice is in need of ways to better conceptualize the interactions between the social, environmental, and economic dimensions of sustainability so that opportunities for simultaneous improvement in human and ecological well-being can be identified more readily" (Smith 2011: 1);

- "People with a broad interdisciplinary outlook [...] are being sought out to offer systemic approaches that are capable of dealing with the complexity of the problems and the tasks we face", (Crofton 2000: 400).

Principles and rules underlying the complexity of the problems and the tasks we face, then, are to be identified and operationalized, as well as well-grounded theoretical frameworks that can offer general-level interpretation schemes and models that are capable of supporting the understanding of complex phenomena, and suffer less from the passing of time.

Therefore, comprehensive frameworks capable of supporting the shift from a simple combination of knowledge to the required integration seem to be still missing. If we agree that "What we observe is not nature itself, but nature exposed to our method of questioning" (Heisenberg, 1958: 57 ), then the method of questioning adopted is determinant to the understanding of any experienced phenomenon and always affects the cognitive interpretation process and its outcomes (Barile 2009).

On the basis of these premises, this Special Feature has been launched to collect contributions from various disciplinary domains that propose frameworks of reference that can be easily shared among scholars and professionals to contribute to the building of a comprehensive body of knowledge for sustainability science.

This Special Feature is one of the outcomes of the WOSC 2017, the 17th edition of the Congress of the World Organization of Systems and Cybernetics, a world organization that invites scientists, policy-makers, professionals, and students across the globe to contribute to the debate of the dynamics underpinning contemporary societal problems from cybersystemic perspectives. WOSC offers a space for conversations about social dynamics from multiple points of view. A call for multidisciplinary approaches launched to collaborate to the creation of inter- and trans-disciplinary knowledge within the shared theme of problem-solving and decision-making in the twenty-first century. Multiple conversations have helped to integrate the variety of themes in the construction of the WOSC 2017s' agenda that has been highly participative valorising diversity within the overarching theme of "Science with and for Society-Contributions of Cybernetics and Systems".

To be effectively addressed, the challenge of sustainability requires research and education to move from a merely descriptive-analytic mode towards a transformational one. These fundamental requirements imply a strong collaborative commitment of Science, Policy and Society towards the envisioning and realization of a Sustainable Future. Hence, this Special Feature aims to offer a contribution to the development of general reference frameworks that can support the understanding of issues related to "people, technology, and governance for sustainability" by adopting systems and cyber-systemic perspectives.

In what follows, we first briefly discuss the main contribution of systems thinking as a paradigm useful to interpret and address the complexity of sustainability issues at methodological and practical level. Subsequently, we illustrate the contents of the papers included in this Special Feature. Finally, we outline some concluding remarks.

\section{The contribution of systems and cybersystemic thinking to sustainability}

\section{Systems and cybersystemic thinking}

The complexity of sustainability is ever more widely recognised. Parallel to this, the need of a systems approach is ever more widely recognised and linked to the need of overcoming still-dominant reductionist approaches. It has been argued: "Integrated assessment of sustainable systems cannot be accomplished by simply linking together a collection of domain specific models. To assess the higher order interactions among interdependent systems requires new tools to capture the emergent behaviours and dynamic relationships that characterize complex, adaptive systems" (Fiksel 2006: 17).

There is a long tradition of systems thinking contributions to social sciences coming from various disciplinary domains (Buckley 1968, 2009; Emery 1969). The origins of systems thinking trace back to the first decades of the twentieth century, although fundamental concepts used in systems thinking can be found in ancient philosophers' thought, like the foundational Aristotle's form-substance dichotomy. Systems thinking is at the basis of many disciplines ranging from biology (Maturana and Varela 1975), ecology (Hannan and Freeman 1977) and sociology (Clark 1993). Bogdanov (1913) was the first to build a 'science' of 
structure based on the principles of organization. However, the main reference for a general systems theory is the work of von Bertalanffy (1968a, 1968b), while the contribution of cybernetics is due to the work of Stafford (Beer 1972a, b, 1985).

As highlighted by Espejo in the WOSC presentation of themes (http://wosc2017rome.asvsa.org/index.php/con gress-information/themes-and-tracks), the main contribution of systems and cybersystemic is their focus in addressing emergent behaviours and dynamic relationships of complex systems, like those that typically characterize sustainability issues, is twofold WOSC. At one level, systems thinking can contribute to disclose sustainability problems that are deeply rooted in our societal structures and culture. Explanations of unsustainability at this level derive from an imbalance between limited cognitive, emotional and organizational capabilities of individuals and institutions on one hand, and overly complex and highrisk technologies and production systems on the other hand. At another level, systems thinking can help to disclose the epochal conditions of possibility of the crisis. Both levels are needed to understand the deep dynamics of unsustainability.

The fundamental aspect that grounds the validity (and the necessity) of systems thinking as an approach to both understand and govern sustainability issues is the inherent systemic functioning of any kind of environmental, social and economic phenomenon. They are all systems, and what is more relevant, they are all interconnected.

Fundamentally, "what we know about all systems is that they bring forth emergent properties that are always different from the sum of their component parts. Systems cannot be understood by focusing on their parts alone if we are to have any hope of understanding that at all" (Robertson 2014: 309).

Interconnections are the key for the systemic functioning of observed phenomena, and systems thinking can help recognizing and understanding the relevance and importance of these interconnections: "this is essential for understanding the nature of sustainability crises we face and therefore in finding solutions" (Stibbe 2009: 85).

To develop and use such ability, what is needed is a support at both methodological and practical levels. Here, cybernetics integrates the contribution of systems thinking. As clarified by Espejo (2018), systems thinking can help in visualising wholeness and avoiding dysfunctional fragmentation. On the other hand, cybernetics helps understanding how to achieve and maintain stability in the interactions between people, institutions and organizations. Therefore, systemic thinking provides methodological tools and is complemented by cybernetics that provides tools to manage the emergent complexity, from the local to the global.
Therefore, the systems perspective can be adopted, on one hand, as a lens for interpreting sustainability recognizing its inherent systemic nature and, on the other hand, integrated with cybernetics, as a tool for approaching the governance and management of sustainability.

To recognise how present-day can be the necessity of systems thinking, it is useful to go back to the motives that, in the late 1970s, according to von Bertalanffy (1968b: 11), led to postulate a general theory of systems:

1. "Up to recent times the field of science as a nomothetic endeavour, i.e., trying to establish an explanatory and predictive system of laws, was practically identical with theoretical physics [...].

2. In the biological, behavioral and sociological fields, there exist predominant problems which were neglected in classical science or rather which did not enter its considerations [...].

3. This in turn was closely connected with the structure of classical science [...].

4. What has been said are not metaphysical or philosophic contentions. [...].

5. It therefore appears that an expansion of science is required to deal with those aspects which are left out in physics and happen to concern the specific characteristics of biological, behavioral, and social phenomena."

After almost 50 years, these motives appear still valid and systems theory reliable to ground a systems study of observed phenomena to account for their complex behaviour.

Essentially, systems thinking and the systems approach imply (Mingers and White 2009):

- Viewing the situation holistically as a set of diverse interacting elements within an environment;

- Recognising that the relationships or interactions between components are more important than the components themselves in determining the behaviour of the whole system;

- Recognising a hierarchy of levels of systems and that systemic properties emerge at different levels and there is a mutual causality within and between levels;

- Accepting that people will act in accordance with differing purposes or rationalities.

\section{Systems thinking and systems approaches}

Systems thinking is a set of general interpretation schemes that inform systems approaches. Over time, interest of scholars for the development of formalized systems approaches has grown (Churchman 1968; Klir 1969; Weinberg 1975; Gharajedaghi 1999; Haines 2000; 
Daellenbach and McNickle 2004; Ashby 2009; Barile 2009; Golinelli 2010).

Different approaches to systems thinking, hence different ways to apply systems thinking as a methodological approach, can be traced to the distinction, established by Checkland (1981) in the book Systems Thinking, Systems Practice, between 'hard' and 'soft' systems thinking. In hard systems thinking, "the world can be taken to be a set of interacting systems, some of which do not work very well and can be engineered to work better" (Checkland 1981: A10). In soft systems thinking, "the world is taken to be very complex, problematical, mysterious. However, our copying with it, the process of inquiry into it, it is assumed, can itself be organized as a learning system. Thus, the word 'systems' is applied to the process of our dealing with the world." (Checkland 1981: A10).

A systems approach is substantially viewed as opposite to a reductionist approach. A comparison between the reductionist and the systems approach is provided in Table 1. It should be said, however, that the systems approaches do not neglect the validity of the reductionist approach per se; rather, it can be successfully adopted for analytical purposes but it fails in understanding the dynamic functioning of a phenomenon, which is always the outcome of interaction processes emerging from its connected components.

As a general theory perspective (Ashby 1958; von Bertalanffy 1968a), systems thinking can effectively provide the knowledge required to support the interpretative approach necessary to recognise the interconnectedness of dynamics of the observed reality. This interconnectedness gives rise to complex recursive structures that emerge from the whole network of relationships characterizing the way reality appears organized. Recognizing these recursive structures is fundamental to have a hope to govern its emerging complexity, like in the case of sustainability issues. Hence, to understand the complexity of systems, understanding recursion is fundamental.

Recursion is a concept well studied by cybernetics and other streams of systems thinking. It is, for example, the core of the Systems Model of Stafford Beer that has been a milestone of cybernetics applied to management marked with the book Brain of the Firm (1972).

Among the numerous scholars who developed the original model of Beer, for example in the scientific context of management (Yolles 1999), Espejo is one of the main references. In the early 1970s, during the Allende's government in Chile, Raul Espejo was Operational Director of the CYBERSYN project under the scientific direction of Stafford Beer. As President of the WOSC, he is now successfully promoting scientific collaboration among scholars from many diverse disciplinary domains from all over the world as a response of Science to the challenges posed by modern Society.

Following the Beer's and Espejo's work (Beer 1972; Espejo and Harnden 1989), during the last decades, a stream has been developed in the field of management studies, that moves from re-exploring the systems roots of management and governance of organizations to account for the increasing failures in facing the growing complexity (Tainter 1988; Waldrop 1992; Mitchell 2009). As an interpretative framework that supports a governance methodology for organizations as well as any entity viewed as a viable system, the viable systems approach $(v S A)$ (Barile 2000, 2009; Golinelli 2010; Barile and Saviano 2011; Barile et al. 2012a, b; Pels et al. 2014) has been developed moving from the original Beer's definition of Viable System as a system that "survives, remains united, is integral, is homeostatically balanced both internally and externally, and possesses mechanisms and opportunities for growth, learning, development, and adaptation, which allow it to become increasingly effective within its environment "(Barile and Saviano 2018: 4).

The Viable Systems Approach ( $v S A$ ) is a systems theory (von Bertalanffy 1968a, b) in which the observed entities and their environment are interpreted through a systemic perspective, overcoming the limits of a reductionist approach and shifting from the analysis of component parts or structures (Parsons 1971) to the wholes (Capra 1996). Regarding interaction, the assumption of the $v S A$ is that each entity/system is related to other systems, called suprasystems, whose traits can be detected in their own subsystems. According to $v S A$, every entity (a firm, or simply
Table 1 Comparing the reductionist and the systems approaches Source Leonard and Beer 1994: 1

\begin{tabular}{ll}
\hline Reductionist approach & Systems approach \\
\hline Focuses on parts & Focuses on wholes \\
Linear causality A causes B & Circular causality A causes B causes C causes A \\
Observer status objective & Observer status subjective \\
Context not very relevant & Context highly relevant \\
One 'truth' or best answer & Multiple truths and answers \\
Externalities not important & Externalities important \\
Problems solved & Problems dissolved \\
\hline
\end{tabular}


an individual or a community) as a system can be considered as a microenvironment, made up of a group of interlinked sub-components that aim towards a common goal (this is the condition, for the aggregate, to be qualified as a system). Networked and interconnected systems of systems become eco-systemic contexts for any entity that lives within them, influencing and being influenced by their behaviours. In these ecosystemic contexts, the structural boundaries among the component parts vanish when interaction emerges (Barile et al. 2012b). Five foundational principles inform the $v S A$ understanding of viable systems' behaviour (Barile 2009; Barile et al. 2018b):

1. Survival: a viable system has the aim to survive in a specific context;

2. Eidos: from an ontological point of view, a viable system can be observed from both a structural and a systemic perspective;

3. Isotropy: in terms of behaviour, a viable system distinguishes an area of decision-making and one of action;

4. Acting: its aim is to reach a result, an objective, through the interaction with suprasystems and subsystems from which the system receives, but to which it also supplies directions and rules of behaviour;

5. Exhaustiveness: entities external to the system are also viable systems, and at the same time, components deriving from a higher order level.

These five principles, together with the whole methodology, give account of the interconnected and recursive nature of systems and the subjectivity of interpretation of their behaviour. It should be said, in fact, that $v S A$ takes on a constructivist view of knowledge. Constructivism is "a form of pragmatism and shares with it the attitude towards knowledge and truth" (von Glasersfeld 1989: 124). It is interesting to reflect upon the following sentences that highlight the aspect relevant in the context of our thinking: "constructivism is a theory of knowing, not of being. That a model of the construction of knowledge could be designed without making ontological claims about what is known, is apparently difficult to accept. [...] And among the scientifically minded the reluctance may spring from the fact that to see the construction of theories as based on autonomous abductions and conceptual assimilation brings with it the realization that the responsibility for the gained knowledge lies with the constructor" (von Glasersfeld 2001: 10-11).

\section{Systems thinking and sustainability}

In the problematic context defined by sustainability, systems thinking, as a governance and management approach rooted in systems theory, is prominently proposed as a way to conceptualize and act toward the integration of the economic, social, and environmental dimensions of sustainability supporting communities "to nurture both human and ecosystem well-being." (Smith 2011: 1).

From a systems perspective, sustainability has been defined as "the ability of systems to persist, adapt, transform or transition in the face of constantly changing conditions." (Williams et al. 2017: 13). Regarding the understanding and the approach to sustainability, Clayton and Radcliffe (1996), are firmly convinced that it cannot be addressed without the adoption of a systems approach. They affirm, in fact, that "To understand sustainability [...] requires some understanding of the behavior of systems in general and of human and environmental systems in particular', (Clayton and Radcliffe 1996: 6).

A recent literature review of systems thinking as a theoretical lens to better understand sustainability management, conducted by Williams et al. in 2017, evidences the increasing attention to the potential of systems thinking in sustainability management research. Results illustrate the exponential increase in publications on systemic dimensions of sustainability management. The study also emphasises that research is still largely fragmented and marginal to the mainstream management journals with the Journal of Cleaner Production in a leadership position as the primary publication outlet for systems thinkers. Five core theoretical concepts emerge from the literature review, which are used to understand sustainability from a systems thinking perspective (Table 2).

The explanations of the five concepts reported in the table consider, in effect, the perspective of organizations (Khailov 2009), and refer to a managerial studies context. However, as management represents a discipline transversal to many problematic contexts and ever more interested in complexity, the explanations of the five core concepts can be generalized suggesting specific recommendations for the governance of sustainability and decision making, as follows:

1. Interconnectedness - it is important to recognise the complexity of interconnected environmental, social and economic problems;

2. Feedbacks - it is important to recognise non linear dynamics of systems and understand the underlying governance mechanisms;

3. Adaptive capacity/resilience-it is important to recognise the adaption mechanism of organizations to changing environmental conditions;

4. Self-organization - it is important to recognise the selforganization processes that lead to emergence dynamics;

5. Emergence-it is important to recognise that existing structures can hinder future emergence. 
Table 2 Core theoretical concepts to understand sustainability from a systems thinking perspective Source adapted from Williams et al. 2017: 50

Core theoretical concepts of systems thinking for sustainability

Interconnectedness

Organizations are agents in interconnected social, economic and ecological systems

Interaction with and reaction to feedbacks causes non linear dynamics and the emergence of complex behaviours over time

Adaptive capacity/resilience

Adaptive capacity ensures the survival of the system whenagents learn from their experience and act accordingly

Self-organization

Self-organizing systems develop their own structure and behaviour spontaneously without being guided from the top down

Emergence

Emergence is the result of lower level interactions when the system is pushed out of equilibrium
Reference sources in management reserach

\author{
Davis et al. (2009) \\ Metcalf and Benn (2013) \\ Sterman (2001) \\ Valente $(2010,2012)$ \\ Sterman (2001) \\ Valente (2010) \\ Whiteman et al. (2004) \\ Ashton (2009) \\ Beermann 2011 \\ Valente (2010) \\ Winn et al. (2011) \\ Batten (2009) \\ Sterman (2001) \\ Rotmans and Loorbach (2009) \\ Whiteman et al. (2013) \\ Dougherty and Dunne (2011) \\ Ehrenfeld (2007) \\ Huo and Chai (2008) \\ Rotmans and Loorbach (2009)
}

As it has been interestingly noted, "recognizing the interconnections within systems and between systems, and exploring the relationship which these interconnections represent, is a learning pathway to a systems thinking perspective" (Stibbe 2009: 88). Interconnections are, therefore, the most relevant aspect in the governance of sustainability, and systems thinking is the possible key to their understanding.

To a deeper understanding, it is worth evidencing that all of the above-listed core concepts can be traced to the complex adaptive nature (Gell-Mann 1992) of social-ecological systems that characterize most of the contexts of the human-nature relationship. As highlighted by Ostrom (2009), the study and governance of social-ecological systems has traditionally suffered from the separation of disciplinary knowledge. The problem worsens if we consider the complex systemic functioning of socio-technical systems that interact with and within social-ecological systems (Redfield 2009).

As argued by Fischer et al. (2015), the concept of social-ecological system has been useful for understanding the interlinked dynamics of human-nature relationships, by increasing recognition of the dependence of humanity on ecosystems, improving collaboration across disciplines, and between science and society, increasing methodological pluralism and increasing consideration of social-ecological interactions in policy frameworks. However, "despite these advances, the potential of a social- ecological systems perspective to improve sustainability outcomes has not been fully realized" (Fischer et al. 2015: 144).

To more effectively account for the complexity of sustainability issues, appropriate approaches are required (Meadows 2008). In particular, "Due to the complexity of coupled systems, researchers should explore the simultaneous use of multiple models that reflect different system interpretations or stakeholder perspectives" (Fiksel 2006: 20). The simultaneous use of multiple models, however, requires researchers be endowed with a kind of knowledge that makes their interpretation schemes flexible and adaptable to the specificity of the different problems and contexts under focus.

The briefly reported fundamentals of systems and cybersystemic thinking for sustainability highlight key requirements in the approach to both understand and govern issues related to sustainability and sustainable development. Hence, systems and cyber-systemic thinking are called to support both the knowledge creation process within and outside science, and its application to policy and organizations' decision making (Golinelli et al. 2015). Education should play a key role as well, in a multi-actor collaborative context, provided that social learning is a key mechanism to realize the cultural change required to the transition toward sustainability (Saviano et al. 2018a, b; Goekler 2003; Wiek et al. 2011). As Wiek et al. (2012) noted, however, "research and education are valuable 
but not sufficient contributions to solving sustainability problems $[; \ldots]$ collaboration and partnerships with and across different stakeholder groups are critical conditions for sustainability science and its real-world impacts (Blackstock et al. 2007; Whitmer et al. 2010; Spangenberg 2011; Talwar et al. 2011)". It has been underlined, in fact, that "Progress in theory-based research needs to be balanced with exploratory policy implementation that will enrich our understanding of sustainability issues in realworld systems" (Fiksel 2006: 20).

To foster a broader adoption of a systems approach to sustainability, it is recommended to (Fiksel 2006):

- Foster trans-disciplinary collaboration in university research;

- Improve communication to educators, government, the media and the general public;

- Develop policy-formulation tools that recognise the complex, interconnected nature of ecological and socio-economic systems;

- Explore ways to introduce an awareness of ecological systems into commerce;

- Develop mechanisms for integrated dialogue among industry, government and academia, shifting from an adversarial to a cooperative approach.

Accordingly, the WOSC 2017 Congress promoted a boundary-crossing knowledge creation process under the overarching framework offered by systems and cybernetics. The outcomes of the WOSC 2017 have helped to explore, debate, and clarify "what kinds of complexity management strategies are more likely to focus our societal and individual actions on desirable directions of sustainability, inclusion, mutual respect, democracy, effective organisation, and quality of life. The challenge is making these strategies functional to societal and individual interests and not to the interests of the few." (Espejo 2018 forthcoming).

\section{People, technology, and governance for sustainability: the contributions of systems and cyber-systemic thinkers}

This Special Feature stems from and expands on the outcomes of the WOSC 2017 Congress exploring and advancing the contribution of systems and cybersystemic thinking to the understanding and governance of sustainability.

Various tracks have been proposed under the macrotheme "People, technology, and Governance for Sustainability":

1. Human aspects of managing systems;

2. Smartness and sustainability;

3. Smart technologies and big data;
4. The brain of the future;

5. Governance in the Anthropocene

As underlined in the presentation of the WOSC themes and tracks (Barile et al. 2018c; http://wosc2017rome.asvsa. org/index.php), the human aspects of managing systems open the space for psychological and social reflexions about interactions among us and with others in the environment. Interactions within organizations and between them and their environments give us the handle to discuss today's lack of fitness of governance in the Anthropocene; our society and its institutions need effective learning mechanisms, so far lacking, to cope with a fragile environment and face the limited rationality in decision-making (Simon 1991). Current information technology offers tools to foster smartness in the quest for sustainability (Aquino et al. 2018). Effective communication and smart technologies make more likely organizational structures sensitive to changing environments and able to distribute scalable responses from the local to the global. The application of digital technologies in organizations is disrupting their structures and increasing their capabilities to deal with complexity and interactions. They are offering potentials for better organizational structures and more effective processes of governance. Cognitive machines, algorithms, deep learning, big data are all contributing to the brain of the future; while they amplify human capabilities, they may help introducing constraints in the environment to avoid overwhelming us with irrelevant complexity.

Approaches based on systems and cyber-systemic thinking are adopted by the authors to offer theoretical and empirical as well as conceptual contributions for addressing the governance of sustainability issues. Authors' contributions have been grouped in the following four subthemes:

\section{Systems and cyber-systemic approaches and frameworks to address the complexity of governance for sustainability}

This first group of articles provide contributions to the theme under focus by proposing systems and cyber-systemic approaches and frameworks developed to address the complexity of governance for sustainability.

Addressing the complexity of governance in the Anthropocene is the aim of the work by Ison et al. Who highlights that empowered capabilities are necessary for dealing with such complexity and uncertainty. The authors discuss, in particular, the effectiveness of governing social-biophysical dynamics constrained by current processes and systems of government, where governance deficits emerge in multiple domains, especially when 
complex large-scale social-biophysical systems are to be governed. The authors also discuss the failure in institutionalising capability for governing wicked problems that are relevant to sustainability science and Anthropocene governance. Through the analysis of two cases studies, Ison et al. highlights how systemic dynamics of governing operate and fail, concluding that innovations are to be developed to build the capacity necessary to address the uncertainties of the Anthropocene by incorporating cybersystemic thinking/practices that can contribute to enhance the empowerment and creativity underpinning sustainability science.

Saviano et al. address the call of systems thinkers for overarching reference frameworks aimed to address the need to overcome fragmentation of knowledge necessary to understand complex sustainability issues, and the need to strengthen the science-policy-industry interface for effectively co-creating knowledge and solutions for sustainability. They propose an advanced version of a triple helix model for sustainability as a basis for elaborating on the conditions for knowledge co-creation and effective science-policy-industry collaboration. Key of the proposed model is the contribution of systems thinking which can provide a bridging perspective aimed to integrate the various disciplines addressing sustainability and the different 'interface' roles of science-policy-industry key actors.

Schwaninger's paper provides a structural framework for restoring the ecological balance of our planet, highlighting the fundamental contribution of cybernetic-systemic approaches in the quest for ecological recovery. This contribution lies in facing the complexity of ecological recovery through the use of new, trans-disciplinary and non-reductionist ways of systems design for renewing sustainability. The cybernetic viable system model is proposed as a frame for sustainable development, explaining how clearly-defined organizational structures can support the achievement of viability in any human or social system. The fundamental concept of recursive organization is exemplified in the design model, including all organizational levels of recursion, from individual to world.

The theme of governance for sustainability is also the core of the work by Scalia et al. that discusses the use of Elkington's Triple Bottom Line and the Etzkowitz's Triple-helix representations as reference models in developing frameworks for addressing sustainability. The authors argue that a gap in literature emerges regarding applications and examples, especially in the field of inquiry defined by sustainability, compared to the discussion about criteria and method of the models that is instead, richer. With the aim of providing a contribution to cover this gap, Scalia et al. draw a more general view from the triple bottom line model discussing its triplehelix' functioning as proposed in the Triple Helix of
Sustainability. A real example is provided of the systemic functioning of the 'triple-helix' together with a discussion of the use of the model as a reference in the understanding of the complexity of governance for sustainability.

\section{Systems and cyber-systemic models for sustainability}

The following two articles propose the adoption of systems and cyber-systemic perspectives and approaches in the use of measurement and evaluation models for sustainability.

Iandolo et al. discuss the concept of sustainable value and develop a $v S A$-based model which they apply using the System Dynamics (SD) methodology for measuring sustainable value. In the model, the authors account for the subjectivity of value, considering it as a vector quantity, the result of a subjective weighting of different dimensions. The aim of the authors is to translate theory into action by developing a model through which $v S A$ is implemented into an SD model that can be instantiated to specific real cases. The more specific goal is approaching a measurement of sustainable value for business organizations accounting for the subjective perspective of decision makers with reference to the triple bottom line framework. At the same time, the authors provide a first attempt to operationalize the $v S A$.

Knowledge integration and co-production are the themes of the article by Restrepo et al. who propose transdisciplinary approaches to foster sustainable change in social-ecological systems. The authors' focus is on assessing the learning process accounting for the different perspectives of participants, which are not usually central to the evaluation, and on how new knowledge is transformed into action. To discuss these problems, Restrepo et al. analyse a 2-year collaborative learning process that involves multiple farmers' perspectives, and the way farmers' new knowledge is turned into action. The authors use second-order cybernetics and integrate the Control Loop Model with Learning Loops to extend the Kirkpatrick's four-level evaluation scheme. The findings show the importance of knowledge integration and co-production to improve the farmers' ability to address complex sustainability challenges, and the effectiveness of the proposed evaluation scheme to explain learning and empowerment experienced by actors involved in trans-disciplinary research for sustainability.

\section{Systems and cyber-systemic technology for sustainability}

This group of three articles adopts systems and cybersystemic perspectives to deal with different aspects and 
contexts in which technology plays an important role in supporting the transition toward sustainability.

Bifulco et al. discuss this role in urban context. Technologies are investigated regarding their contribution to the achievement of sustainability in the three spheres of planet, profit, and people. Through a content analysis of reports issued by 10 among the cities that are advancing fast to become sustainable, technology results to be an element crossing sustainability which supports, on one hand, cost efficiency and better economic conditions in addressing environmental problems and, on the other hand, the provision of public services for a better quality of life for citizens and cities' stakeholders. The contribution to efficiency of technology is appreciated as sustainable because of a better use of resources helping to manage and lead cities towards more sustainable conditions.

In the subsequent article, Caputo et al. move from recognizing ICT as the key force towards more effective and efficient use of resources. The authors believe that ICTbased knowledge can offer an important contribution to address sustainability, and, on this basis, examine its role in advancing sustainability goals. Focus is on Smart Grid as an example of complex technological contribution to address sustainability. The Smart Grid experience, in the light of systems thinking, shows the links between smartness and sustainability and how ICT can widen the scope of the sustainability "game" also engaging more "players".

Tibau and Zazula address the need of multi-disciplinary collaborative systems for creating sustainable buildings and infrastructure. The study offers evidence of how the participation of multiple disciplines in designing large projects using traditional methods tends to generate entropy that compromises sustainable construction. The authors argue that new approaches based on the systematic digitalization of the building lifecycle, from design to demolition, can contribute to solving the problem by introducing a Building Information Modeling (BIM) systems and big data. The novelty in the use of BIM and big data is in the inclusion of the sustainability perspective in models traditionally focused on construction performance. A new conceptual and technical framework for sustainable management of construction site big visual data is provided.

\section{Systems and cyber-systemic theoretical perspectives and views of sustainability}

The following group of papers address theoretical aspects of sustainability science elaborating on the role that systems and cyber-systemic thinking can perform, at both theoretical and practical level, in bringing a contribution to sustainability science and its role of advancing the expected transformational change and social progress.
In particular, Biggiero proposes a reflection of the identity and theoretical roots of Sustainability Science, especially necessary for its inter- and trans-disciplinary character, which involves a variety of different approaches, theories and practices. The problem with such variety seems to be how to ground it on a reliable and coherent basis. In this respect, Biggiero warns against the risk of a rejection from disciplinary specialized researchers and suggests sustainability science to acknowledge its theoretical roots of systems science and cybernetics to become a powerful reference paradigm for knowledge exchange. Biggiero also recognises, however, that systems science and cybernetics should be more in general better understood and embraced by scholars as sources of knowledge for understanding challenging problems of our society.

By adoption of a systems perspective to discuss the concept of sustainability, Ben Eli proposes to regard sustainability as a system state that is mediated by specific structures. In this way, Ben Eli intends to overcome the more common pure normative interpretation of sustainability. According to Ben Eli, focus on the kinds of structures that mediate a system's state would allow proactive design of structures and mechanisms more effectively capable of producing the change pursued in the sustainability agenda. This transformational change is interpreted as a second-order change, i.e., a change that implies a major shift of the system itself. On this basis, Ben Eli proposes a new definition of sustainability from which five core sustainability principles are derived, which prescribe the conditions for achieving sustainability together with implications and operational guidelines. Particular attention is paid to the necessity of forming an integrated, systemic set, to be acted on simultaneously.

The last article of this group enlarges the perspective focusing on the social progress aspects of sustainability and discussing the division between non-profit and for-profit sectors. Building upon different fields of study that include economics, development studies, and non-profit management, Hysa et al. propose a view of social business as a sustainable business model discussing if the Social Business (SB) is capable of solving the problems that arise in society, changing the boundaries between the private, public and non-profit sectors. In the view of the authors, the social business may solve social, economic, and environmental problems proving to be by default a sustainable business model that respects the triple bottom line approach.

\section{Concluding considerations}

With the aim of addressing, in particular, issues regarding people and technology related to the governance for sustainability, the articles collected in this Special Feature 
highlight the contribution of systems and cyber-systemic thinking, modelling and epistemology. They are the outcomes of knowledge co-creation processes and articulated methodologies and perspectives that involve a network of scientists, practitioners, and researchers from various disciplinary domains and countries around the world.

In particular, these articles represent the responses of systems thinkers to the call to join the transdisciplinary academic community hosted by Sustainability Science journal and contributes to the "discovery process that fuses the natural sciences, social sciences, economic sciences and humanities" it promotes (https://link.springer.com/ journal/11625). Hence, they offer a contribution to the understanding of "interactions between global, social, and human systems, the complex mechanisms that lead to degradation of these systems, and concomitant risks to human well-being." (https://link.springer.com/journal/ 11625).

This Special Feature, whose aim is to strongly affirm that the challenges posed by sustainability cannot be effectively understood, hence addressed, without the interpretative support of systems thinking, opens up multiple research trajectories, especially fostering collaboration with other scientific communities that act in different disciplinary domains and are ever more engaged to the sustainability challenges (Lusch and Spohrer 2012; Golinelli et al. 2015) and open minded (Mitroff and Linstone 1993). The various trajectories are illustrated along the discussion in this editorial and in the papers included in this Special Feature.

Be it a hard or a soft adoption of systems thinking, its principles throw light on the otherwise mysterious world of sustainability and sustainable development.

Be it people or technology to lever the one used to apply systems thinking, it always shows an incomparable power: simplify what inevitably appears complex to the eyes of any observer.

Acknowledgements The Guest Editors would like to thank the editorin-chief Professor Kazuhiko Takeuchi for the opportunity to edit this Special Feature, and Doctors Darek Gondor and Osamu Saito (Editorial Office) for the fundamental support during the editorial process. The guest editors would also like to thank professor Raul Espejo, president of the World Organizations for Systems and Cybernetics, for having introduced them to the stimulating debate and challenges posed by cyber systemic thinkers community, therefore triggering the production of this Special Feature. A special thought on the part of the guest editors goes to Philip Wallis, co-author of the first article of this Special Feature. We join the dedication of Ray Ison to his memory and would like to express our affection to his partner and his sons.

\section{References}

Aquino RP, Barile S, Grasso A, Saviano M (2018) Envisioning smart and sustainable healthcare: $3 \mathrm{D}$ printing technologies for personalized medication. Futures. https://doi.org/10.1016/j. futures.2018.03.002

Ashby WR (1958) General systems theory as a new discipline. Gen Syst 3:1-6

Ashby WR (2009) Principles of the self-organizing system. In: Buckley W (ed) Systems research for behavioural science. Aldine Transaction, New Brunswick, pp 108-122

Ashton WS (2009) The structure, function, and evolution of a regional industrial ecosystem. J Ind Ecol 13(2):228-246

Barile S (2000) Contributi sul pensiero sistemico in economia d'impresa. Centro Studi di Tecniche Aziendali, Atripalda

Barile S (2009) Management sistemico vitale, vol 1. Giappichelli, Torino

Barile S, Saviano (2011) "Foundations of systems thinking: the structure-system paradigm", in various authors, contributions to theoretical and practical advances in management. A viable systems approach (vSa), International Printing, Avellino, pp. $1-25$

Barile S, Saviano M (2018) Complexity and sustainability in management: insights from a systems perspective. Social dynamics in a systems perspective. Springer, Cham, pp 39-63

Barile S, Pels J, Polese F, Saviano M (2012a) An introduction to the viable systems approach and its contribution to marketing. J Bus Mark Manag 5(2):54-78

Barile S, Saviano M, Polese F, Di Nauta P (2012b) Reflections on service systems boundaries: a viable systems perspective: the case of the London Borough of Sutton. Eur Manag J 30(5):451-465

Barile S, Pellicano M, Polese F (2018a) Social dynamics in a systems perspective. Springer, Berlin

Barile S, Quattrociocchi B, Calabrese M, Iandolo F (2018b) Sustainability and the viable systems approach: opportunities and issues for the governance of the territory. Sustainability 10(3):790

Barile S, Espejo R, Perko I, Saviano M (2018c) Cybernetics and systems. Social and Business Decisions, Routledge-Giappichelli, London

Batten DF (2009) Fostering industrial symbiosis with agent-based simulation and participatory modeling. J Ind Ecol 13(2):197-213

Beer S (1972a) Brain of the firm. The Penguin Press, London

Beer S (1972b) Brain of the firm. Allen Lane, Penguin, Hardmondsworth

Beer S (1985) Diagnosing the system for organizations. John Wiley, London

Beermann M (2011) Linking corporate climate adaptation strategies with resilience thinking. J Clean Prod 19(8):836-842

Best A, Holmes B (2010) Systems thinking, knowledge and action: towards better models and methods. Evid Policy J Res Debate Pract 6(2):145-159

Blackstock KL, Kelly GJ, Horsey BL (2007) Developing and applying a framework to evaluate participatory research for sustainability. Ecol Econ 60:726-742

Bogdanov AA (1913) Theory of organization, or Tektology. Moscow

Buckley W (1968) Modern systems research for the behavioural scientist. Aldine Transaction, New Jersey

Buckley W (2009) Systems research for behavioural science. Aldine Transaction, New Jersey (Originally published: modern systems research for the behavioural scientist, 1968)

Capra F (1996) The web of life. Audio renaissance tapes. Anchor Books, Hamburg, pp 153-171

Checkland PB (1981) Systems thinking, systems practice. John Wiley, New York

Churchman CW (1968) The systems approach. Dell Publishing, New York

Clark A (1993) Associative engines. MIT Press, Boston 
Crofton F (2000) Educating for sustainability: opportunities in undergraduate engineering. J Clean Prod 8(5):397-405

Daellenbach H, McNickle D (2004) Management science: decisionmaking through systems thinking. Palgrave Macmillan, London

Davis C, Nikolić I, Dijkema GPJ (2009) Integration of life cycle assessment into agent based modeling. J Ind Ecol 13(2):306-325

Dougherty D, Dunne DD (2011) Organizing ecologies of complex innovation. Organ Sci 22(5):1214-1223

Ehrenfeld JR (2007) Would industrial ecology exist without sustainability in the background? J Ind Ecol 11(1):73-84

Emery F (ed) (1969) Systems thinking. Penguin Books, Harmondsworth

Espejo R (2018) Introduction. In: Barile S, Espejo R, Perko I, Saviano $M$ (eds) Cybernetics and systems. social and business decisions. Routledge-Giappichelli, London

Espejo R, Harnden R (1989) The viable systems model-interpretations and applications of Stafford Beer's VSM. Wiley, Chichester

Fiksel J (2006) Sustainability and resilience: toward a systems approach. Sustain Sci Pract Policy 2(2):14-21

Fischer J, Gardner TA, Bennett EM, Balvanera P, Biggs R, Carpenter S, Daw T, Folke C, Hill R, Hughes TP, Luthe T, Maass M, Meacham M, Norström AV, Peterson G, Queiroz C, Seppelt R, Spierenburg M, Tenhunen J (2015) Advancing sustainability through mainstreaming a social-ecological systems perspective. Curr Opin Environ Sustain 14:144-149

Gell-Mann M (1992) Complexity and complex adaptive systems. Santa Fe Institute Studies in the Sciences of ComplexityProceedings. Addison-Wesley Publishing Co, boston, p 177

Gharajedaghi J (1999) Systems thinking: managing chaos and complexity. Butterworth Heinemann, Boston

Goekler J (2003) Teaching for the future: systems thinking and sustainability. Green Teach 70:8

Golinelli GM (2010) Viable systems approach (VSA): governing business dynamics. Cedam Kluwer, Padua

Golinelli GM, Barile S, Saviano M, Farioli F, Yarime M (2015) Towards a common framework for knowledge co-creation: opportunities of collaboration between service science and sustainability science. In: Gummesson E, Mele C, Polese F (eds) Service dominant logic, network and systems theory and service science: integrating three perspectives for a new service agenda. Giannini, Napoli

Haines S (2000) The systems thinking approach to strategic planning and management. St Lucie Press, London

Hannan MT, Freeman J (1977) The population ecology of organizations. Am J Sociol 82(5):929-964

Heisenberg W (1958) Physics \& philosophy. The revolution in modern science. George Allen \& Unwin, Arena

Holling CS (2001) Understanding the complexity of economic, ecological, and social systems. Ecosystems 4(5):390-405

Huo CH, Chai LH (2008) Physical principles and simulations on the structural evolution of eco-industrial systems. J Clean Prod $16: 1995-2005$

Ison (2017). http://wosc2017rome.asvsa.org/. Accessed July 2018

Khailov KM (2009) The problem of systemic organization in theoretical biology. In: Buckley W (ed) Systems research for behavioural science. Aldine Transaction, New Brunswick, pp 45-50

Klir GJ (1969) An approach to general systems theory. Van Nostrand Reinhold Co., New York

Komiyama H, Takeuchi K (2006) Sustainability science: building a new discipline. Sustain Sci 1:1-6. https://doi.org/10.1007/ s11625-006-0007-4

Leonard A, Beer S (1994). The systems perspective: methods and models for the future. AC/UNU Project. http://citeseerx.ist.psu. edu/viewdoc/download?doi=10.1.1.20.9436\&rep=rep1\&type $=$ pdf. Accessed July 2018

Lusch RF, Spohrer JC (2012) Evolving service for a complex, resilient, and sustainable world. J Market Manag 28(13-14):1491-1503

Maturana HR, Varela F (1975) Autopoietic systems. Rep BCL 9(4):37-48

Meadows DH (2008) Thinking in systems. Chelsea Green Publishing, White River Junction, pp 77-78

Metcalf L, Benn S (2013) Leadership for sustainability: an evolution of leadership ability. J Bus Ethics 112(3):369-384

Mingers J, White L (2009). A review of the recent contribution of systems thinking to operational research and management science. Working paper, Kent Business School, Canterbury

Mitchell M (2009) Complexity. A Guided Tour. Oxford University Press, Oxford

Mitroff I, Linstone H (1993) The unbounded mind: breaking the chains of traditional business thinking. Oxford University Press, Oxford

Orecchini F, Valitutti V, Vitali G (2012) Industry and academia for a transition towards sustainability: advancing sustainability science through university-business collaborations. Sustain Sci 7(1):57-73. https://doi.org/10.1007/s11625-011-0151-3

Ostrom E (2009) A general framework for analyzing sustainability of social-ecological systems. Science 325(5939):419-422

Parsons T (1971) The system of modern societies. Prentice Hall, Englewood Cliffs, NJ

Pels J, Barile S, Saviano M, Polese F, Carrubbo F (2014) The contribution of $\mathrm{VS}_{\mathrm{A}}$ and SDL perspectives to strategic thinking in emerging economies. Manag Serv Qual Int J 24(6):565-591

Redfield R (2009) Levels of integration in biological and social systems. In: Buckley W (ed) Systems research for behavioural science. Aldine Transaction, New Brunswick, pp 59-70

Robertson M (2014) Sustainability principles and practice. Routledge, London

Rotmans J, Loorbach D (2009) Complexity and transition management. J Ind Ecol 13(2):184-196

Saviano M, Di Nauta P, Montella MM, Sciarelli F (2018a) Managing protected areas as cultural landscapes: the case of the Alta Murgia National Park in Italy. Land Use Policy 76:290-299

Saviano M, Di Nauta P, Montella MM, Sciarelli F (2018b) The cultural value of protected areas as models of sustainable development. Sustainability 10(5):1567

Simon HA (1991) Bounded rationality and organizational learning. Organ Sci 2(1):125-134

Smith T (2011) Using critical systems thinking to foster an integrated approach to sustainability: a proposal for development practitioners. Environ Dev Sustain 13(1):1-17

Spangenberg JH (2011) Sustainability science: a review, an analysis and some empirical lessons. Environ Conserv 38:275-287

Sterman JD (2001) System dynamics modeling: tools for learning in a complex world. Calif Manag Rev 43(4):8-25

Stibbe AE (2009) The handbook of sustainability literacy: skills for a changing world. Green Books, Cambridge

Tainter JA (1988) The collapse of complex societies, New York \& Cambridge. Cambridge University Press, Cambridge

Talwar S, Wiek A, Robinson J (2011) User engagement in sustainability research. Sci Public Policy 38:379-390

Valente M (2010) Demystifying the struggles of private sector paradigmatic change: business as an agent in a complex adaptive system. Bus Soc 49(3):439-476

Valente M (2012) Theorizing firm adoption of sustaincentrism. Organ Stud 33(4):563-591

von Bertalanffy L (1968a) General system theory. Wiley, New York, p 40 
von Bertalanffy L (1968b) General system theory-a critical review. In: Buckley W (ed) Modern systems research for the behavioral scientist. Aldine Publishing Company, Chicago, pp 11-30

von Glasersfeld E (1989) Cognition, construction of knowledge, and teaching. Synthese 80(1):121-140

von Glasersfeld E (2001) The radical constructivist view of science. Found Sci 6(1-3):31-43

Waldrop WM (1992) Complexity: the emerging science at the edge of order and chaos. Touchstone, New York

Weinberg GM (1975) An introduction to general systems thinking. Wiley, New.York

Whiteman G, Forbes BC, Niemelä J, Chapin FS III (2004) Bringing feedback and resilience of high-latitude ecosystems into the corporate boardroom. Ambio 33(6):371-376

Whiteman G, Walker B, Perego P (2013) Planetary boundaries: ecological foundations for corporate sustainability. J Manag Stud 50(2):307-336

Whitmer A, Ogden L, Lawton J, Sturner P, Groffman PM, Schneider L et al (2010) The engaged university: providing a platform for research that transforms society. Front Ecol Environ 8(6):314-321

Wiek A, Withycombe L, Redman CL (2011) Key competencies in sustainability: a reference framework for academic program development. Sustain Sci 6(2):203-218

Wiek A, Farioli F, Fukushi K, Yarime M (2012) Sustainability science: bridging the gap between science and society. Sustain Sci 7(1):1-4
Williams A, Kennedy S, Philipp F, Whiteman G (2017) Systems thinking: a review of sustainability management research. J Clean Prod 148:866-881

Winn M, Kirchgeorg M, Griffiths A, Linnenluecke MK, Günther E (2011) Impacts from climate change on organizations: a conceptual foundation. Bus Strat Environ 20(3):157-173

Yarime M, Trencher G, Mino T, Scholz RW, Olsson L, Ness B, Frantzeskaki N, Rotmans J (2012) Establishing sustainability science in higher education institutions: towards an integration of academic development, institutionalization, and collaborations with stakeholders. Sustain Sci 7(Suppl):101-113. https:// doi.org/10.1007/s11625-011-0157-5

Yolles M (1999) Management systems: a viable approach. Financial Times Pitman, London

\section{Websites}

http://wosc.co/. Accessed July 2018

http://www.asvsa.org/. Accessed July 2018

http://www.scienzasostenibilita.org/. Accessed July 2018

https://en.wikipedia.org/wiki/Viable_systems_approach. Accessed July 2018

https://link.springer.com/journal/11625. Accessed July 2018 